\title{
Electrochemical Investigation of the Effect of Activated Coconut Shells in the Negative Plate of Lead Carbon Battery
}

\author{
T.I. Imalerio $^{*} \quad$ G. O. Oyerinde ${ }^{1} \quad$ T.A. Adetula ${ }^{1} \quad$ N.O. Alu ${ }^{1} \quad$ O.A. Babalola ${ }^{1} \quad$ A.A. Sallau ${ }^{2}$ \\ 1.Physics Advanced Research Centre, Sheda Science and Technology Complex, Abuja, Nigeria \\ 2.Chemistry Advanced Research Centre, Sheda Science and Technology Complex, Abuja, Nigeria
}

\begin{abstract}
.
The addition of certain types of carbon or graphite to the negative electrode paste mix of lead acid batteries has been reported to substantially slow down the capacity limiting accumulation of insoluble lead sulfate. The resulting lead carbon battery provides improved capacity and cycle life. This report presents the results obtained from recycling of some used lead acid cells into lead carbon battery negative electrodes through the addition of activated coconut shells mixed with graphite powder. Lead metal pieces and sulfated plate materials were obtained from used batteries. The lead pieces were melted and casted to form new grids. The plate materials were desulfurized and calcined to generate the lead oxide used for the new plates. Five new negative plates $\left(30 \mathrm{~mm}^{2}\right)$ composed of the carbon in the proportions $(0,2,4,6,8) \%$ by volume to the $\mathrm{PbO}$ contents were prepared. The plates were cured at $60{ }^{\circ} \mathrm{C}$ in high humidity for $12 \mathrm{hrs}$. and formed at $5 \mathrm{~mA} / \mathrm{cm}^{2}$ for $12 \mathrm{hrs}$. Cyclic Voltammetry tests implemented with a Gamry 600+ Potentiostat indicated progressive increase in discharge current output with increase in the content of the electroactive carbon up to $4 \%$ carbon loading.
\end{abstract}

Keywords: Lead Carbon battery, Desulfurization, Cyclic Voltammetry, Potentiostat.

DOI: $10.7176 / \mathrm{JNSR} / 9-20-08$

Publication date:October $31^{\text {st }} 2019$

\section{Introduction.}

The lead acid battery (LAB) has been a highly successful rechargeable electrochemical storage system. Despite its design dating from Plante in 1859, the system continues to benefit from new approaches. The recent development of the Ultra Battery ( Mosely et. al., 2006) testifies to this progression. As one of the major types of secondary battery, LAB have been widely used as start-up batteries in internal combustion engine vehicles and in other fields such as energy storage and backup power. In recent years the global production value of LAB has reached 39.2 billion US Dollars, which accounted for $68.2 \%$ of the total global value of secondary batteries. Because of development of the automobile industry in several countries and the requirement of high capacity lead - acid batteries for new blue motion energy saving automobile, the yield of the LAB would promising increase by $5 \%$ in the next 5-10 years. (Pan et al., 2016).

The traditional life - limiting mechanism of the lead acid battery is the formation of insoluble lead sulfate deposits on the plates during discharge. The formation of the deposits is exacerbated under the operating conditions required by many large- scale energy storage systems which cycle at a high electrical current while remaining in a partially charged state (high- rate - partial - state - of charge operation or HRPSoC) (Enos, 2012). This is the prevalent condition in hybrid electric vehicles. Siomi et.al., (1997), reported that increasing the amount of carbon in the negative plate of valve -regulated lead acid battery reduced the lead sulfate accumulation and extended the life performance of the battery. The report stated that carbon formed a conductive network in the $\mathrm{PbSO}_{4}$ particles of the discharged negative plate. Understanding the mechanism by which the resulting lead carbon battery provides enhance performance has recently been a subject of intense study (Calebeck et al., 2006, Moseley et al., 2006, Micka et al., 2009 Fernadez et al., 2011). Jaiswal et al., (2015), studied this phenomenon stating that the presence of carbon at the $\mathrm{Pb}$-interface substantially enhances the electrochemical activity and increases the Faradaic charge, while high surface area carbons add to the capacitive charge. Fernadez et.al., (2015), used Cyclic Voltammetry (CV), Potentiodynamic Polarization (PP), and Electrochemical Impedance Spectroscopy (EIS), to show that the addition of carbon on the $\mathrm{Pb}$ electrode increased anodic and cathodic reactions by tenfold. The work also revealed that the electrochemical active sites for the $\mathrm{PbSO}_{4}$ to nucleate and spread increases upon addition of electrical conductive and high surface area carbons. Hao et al., (2018), presented a detailed review of recent works on the roles of carbon materials in lead-carbon batteries.

According to Pavlov (2006), used LAB contains approximately $\mathrm{PbSO}_{4}(60 \%), \mathrm{PbO} /\left(\mathrm{PbO}_{2}\right) 19 \%, \mathrm{~Pb}(21$ $\%$ ). Depending on the level of mechanization and environmental standards, the Pyro metallurgical Recycling (PMR) of LAB can generate substantial environmental hazards in the forms of soil and groundwater contamination by solid lead and acid spills. Therefore, it appears that the adoption of cleaner technologies at the preprocessing stage in secondary smelter operations can significantly improve the smelter performance from both health and environment perspectives. Consequently, hydrometallurgical approaches are being adopted and currently being described in literature. The method employs desulfurization and leaching of the lead paste to soluble compounds followed by recrystallization and calcination to generate lead oxide powders. As a significant 
clean technology, hydrometallurgical processing produces significantly lower amounts of emissions compared to pyro metallurgical systems.

Activated Carbon (AC) is a form of carbon that has been processed to make it highly porous. About one gram of AC could have a surface area of $500 \mathrm{~m}^{2}$ (Grubs 2009). It is derived from charcoal through pyrolysis and activation. A surface area range of between 446 to $1340 \mathrm{~m}^{2} \mathrm{~g}^{-1}$ has been reported for Coconut shells (Farma et a., 2013). The objective of this work is to present the following :

(1) A simplified process of hydrometallurgical recovery of lead oxide from used lead paste via chemical conversion by desulfurization, and calcination.

(2) Recycling of the recovered ULAB oxides to LCB plates .through the addition of activated coconut shells charcoal mixed with graphite powder.

(3) An electrochemically studied lead based storage battery production / recycling process that releases very negligible lead contaminants into the environment and produces a battery electrode with less quantity of lead at a higher energy capacity.

\section{Methodology}

Preparation process of the coconut shell derived activated carbon has been described elsewhere (Imalerio et al., 2014). ULAB active materials were extracted from three different used batteries. The material was washed in distilled water to remove residual electrolyte. Pole and plate connection lead pieces were separated from the paste materials. The paste materials were dried first in open air for some days and oven dried at $120{ }^{\circ} \mathrm{C}$ for $2 \mathrm{hrs}$. Desulfurization of the paste materials was with ammonium carbonate, and calcined at $450{ }^{\circ} \mathrm{C}$ to obtain lead oxide powders. Additives were Barium sulfate and Sulfonated lignin $(0.2 \%)$.. Five (5) new test negative lead carbon plates composed of electroactive carbons in the proportions $(0,2,4,6,8) \%$ by volume to the $\mathrm{PbO}$ contents were prepared. Figure 1 is a schematic of the utilized Teflon / lead frame electrode prepared for of the each electrodes. Active material surface area was $30 \mathrm{~mm}^{2}$ at a thickness of $1.0 \mathrm{~mm}$.

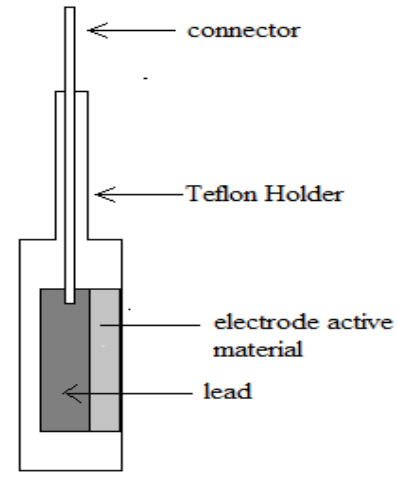

Fig. 1.0: lead / Electrode material Teflon holder.

The hydro-setting curing process which commenced after open air drying for $12 \mathrm{hrs}$ was implemented at a temperature range of ambient to $60{ }^{\circ} \mathrm{C}$ in a moisture saturated curing chamber for another $12 \mathrm{Hrs}$. The chamber was produced in the laboratory. Formation tank parameters were $2.78 \mathrm{VDC}$ and $1.05 \mathrm{sp}$. gr. $\mathrm{H}_{2} \mathrm{SO}_{4}$ with flat lead piece as positive electrode. Tank current was limited to $5 \mathrm{~mA} \mathrm{~cm}$ of plate's surface area. The variable output voltage formation power source was also fabricated in the laboratory. The process was run for $24 \mathrm{hrs}$. On completion the electrodes were rinsed in distilled water and dried in $\mathrm{N}_{2}$ environment for $3 \mathrm{hrs}$. Single electrode characterization was first with voltammetry at Cyclic potential scans of $0.5 \mathrm{mV} \mathrm{s}{ }^{-1}$ within $-0.15 \mathrm{~V}$ to $-0.85 \mathrm{~V}$ in 1.24 sp.gr. Sulfuric acid. Counter electrode was Graphite rod and Reference was $\mathrm{Ag} / \mathrm{AgCl}_{2}$. The applied potential is shown in figure 2.

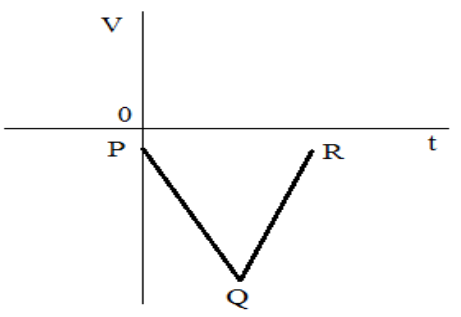

Fig. 2 . Negative Electrode Cyclic Voltammetry Potential Scan.

It starts at point $\mathrm{P}$ peaks at $\mathrm{Q}$, returns to $\mathrm{R}$ and is repeated for several cycles. Ten cycles were used for each of the electrode. Point $\mathrm{P}$ was at $-150 \mathrm{mV}$ and $\mathrm{Q}$ at $-850 \mathrm{mV}$. 
The electrodes impedance variation was recorded also by Galvanostatic Electrochemical Impedance Spectroscopy. The Half Cell configuration frequency spanned $100 \mathrm{mHz}$ to $100 \mathrm{KHz}$ for all the electrodes. The instrument was a Gamry Reference 600+ Potentiostat / Galvanostat / ZRA.

\section{Results}

The methylene blue dye estimated Nano-surface area of the activated carbon was $623.6 \mathrm{~m}^{2} / \mathrm{g}$. Figure 3 , shows the voltammogram at the tenth scan of the plane lead electrode $(0 \% \mathrm{C})$.

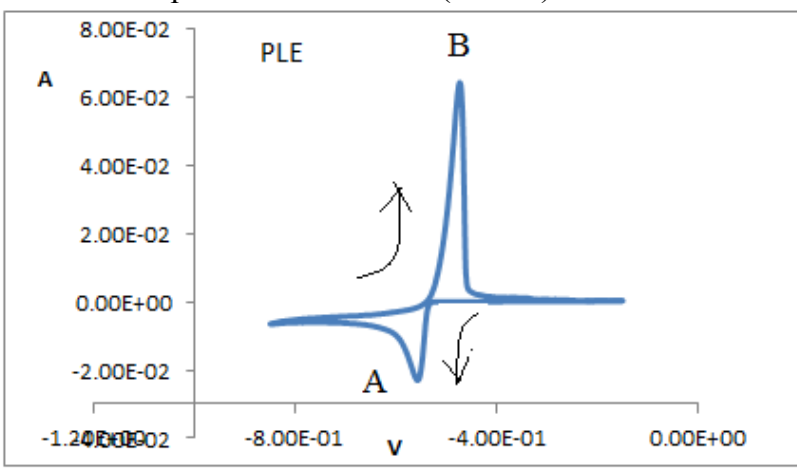

Fig. 3 : Voltammogram of plane lead negative electrode.

Inset is arrows indicating the direction of potential scan and hence plot development as the voltammetry progressed. Peak A corresponding to the negative electrode charge / Reduction peak was -23.04 mA. The discharge oxidation peak at B was $64.22 \mathrm{~mA}$. Figure 4, presents the combined voltammograms of the five prepared electrodes.

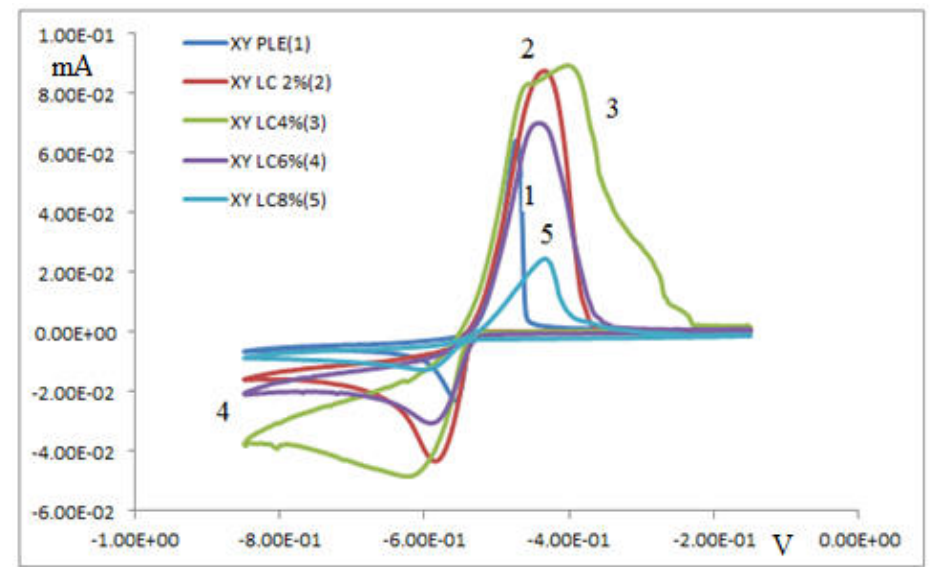

Fig. 4: Voltammogram of Lead carbon electrodes. (- 150 to -850$) \mathrm{mV}$ at $5 \mathrm{mVs}^{-1}$ Test instrument extracted data from the voltammograms is presented in Table 1.

Table 1.0: Lead Carbon Electrodes Cyclic Voltammetry data.

\begin{tabular}{|l|l|l|l|l|l|l|}
\hline \multirow{2}{*}{ Electrode } & \multicolumn{3}{|c|}{ Reduction Peaks A } & \multicolumn{3}{c|}{ Oxidation Peaks B } \\
\cline { 2 - 7 } & $\begin{array}{l}\text { Peak } \\
\text { Current } \\
(\mathrm{mA})\end{array}$ & $\begin{array}{l}\text { Potn. } \\
\text { Ref. } \\
(\mathrm{mV})\end{array}$ & $\begin{array}{l}\text { Integral } \\
\text { Charge }(\mathrm{C})\end{array}$ & $\begin{array}{l}\text { Peak } \\
\text { Current } \\
(\mathrm{mA})\end{array}$ & $\begin{array}{l}\text { Potn. vs Ref. } \\
(\mathrm{mV})\end{array}$ & $\begin{array}{l}\text { Integral } \\
\text { Charge }(\mathrm{C})\end{array}$ \\
\hline PLE & -23.04 & -559.1 & -2.572 & 64.22 & -471.3 & 1.120 \\
\hline LC 2\% & -43.29 & -587.1 & -6.854 & 87.59 & -431.3 & 4.771 \\
\hline LC 4\% & -78.22 & -635.0 & -6.237 & 125.1 & -369.5 & 5.596 \\
\hline LC 6\% & -51.24 & -609.6 & -2.620 & 87.38 & -403.9 & 1.712 \\
\hline LC 8\% & -19.17 & -611.2 & -1.100 & 32.23 & -403.4 & 0,366 \\
\hline
\end{tabular}

Bar graph plot of the peak charging reduction and discharge oxidation plots are presented in figure 5. 


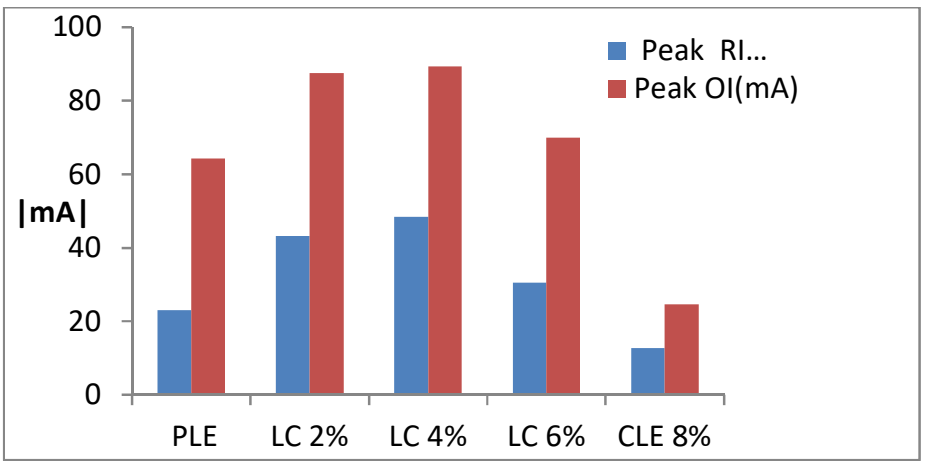

Fig. 5: lead Carbon electrodes peak REDOX currents graph.

Maximum peak charge / discharge currents were recorded at 4\% carbon loading of the negative electrodes. The electrochemical activities accumulated charges obtained by area integration of the voltammograms are plotted in figure 6.

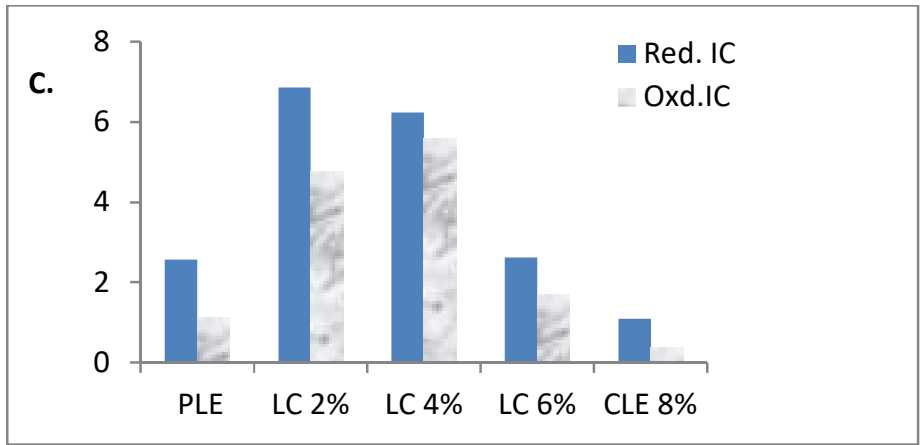

Fig.6: Cyclic Voltammetry Integral charge plots of lead Carbon electrodes.

The plots indicate highest charge storage at $2 \%$ carbon loading.

Bode impedance plots for the five electrodes are presented in figures $7 \mathrm{a}$ nd $7 \mathrm{~b}$. All the plots presented close approximation to the frequency response of the common EIS model Randles plot. Therefore the magnitude of electrolyte resistance (Rs), polarization impedance (Rp) and double layer capacitance (Cdl), could be approximately deduced from the plots. Table 2 presents the extracted values for the Rs and Rp. All the Rs were recorded at $100 \mathrm{Khz}$ and $\mathrm{Rs}+\mathrm{Rp}$ at $0.1 \mathrm{~Hz}$.

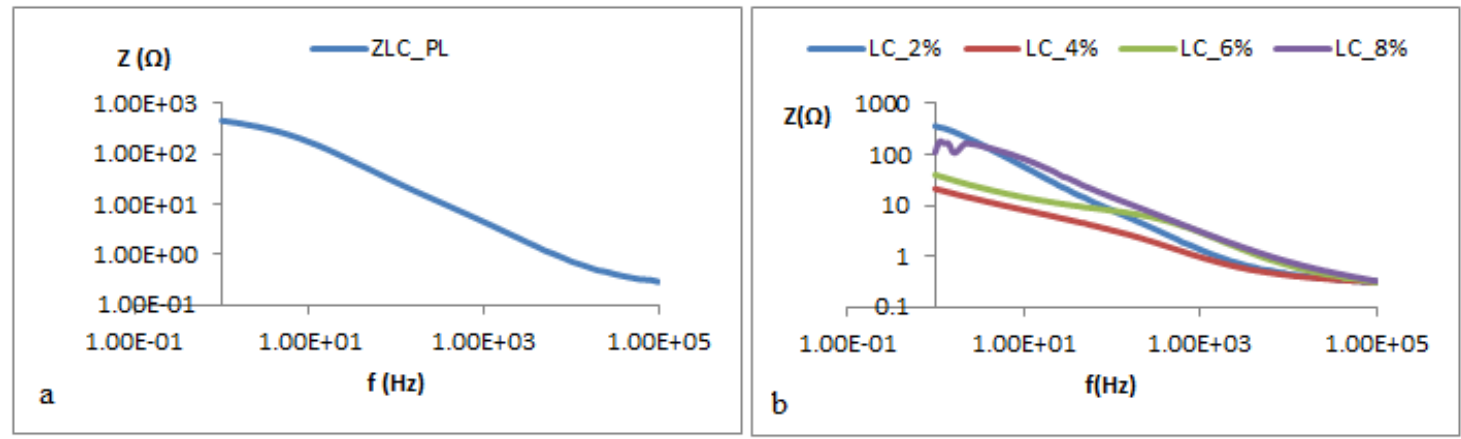

Fig. 7. Bode Impedance plots of (a) Plane lead electrode and (b) lead carbon electrodes.

Table 2: Electrochemical Impedance data for Lead carbon test electrodes.

\begin{tabular}{|c|c|c|c|}
\hline Electrode & Rs ( $(\Omega)$ & $\mathbf{R s}+\mathbf{R p}(\Omega)$ & $\operatorname{Rp}(\Omega)$ \\
\hline PLE & 0.2901 & 461.5 & 461.21 \\
\hline LC $2 \%$ & 0.3259 & 365.11 & 364.78 \\
\hline LC 4\% & 0.3155 & 21.33 & 21.01 \\
\hline LC 6\% & 0.3049 & 40.15 & 39.84 \\
\hline LC $8 \%$ & 0.3258 & 110.11 & 109.78 \\
\hline
\end{tabular}




\section{Discussion}

Cyclic Voltammetry: The curve of the plane lead electrode - figure 3, is a classic voltammogram of the $\mathrm{Pb} / \mathrm{PbSO}_{4}$ redox couple in $\mathrm{H}_{2} \mathrm{SO}_{4}$. Reduction at the negative electrode $\left(\mathrm{PbSO}_{4}\right.$ to $\left.\mathrm{Pb}\right)$ and Oxidation $\left(\mathrm{Pb}\right.$ to $\left.\mathrm{PbSO}_{4}\right)$ represent the charging and discharging of the electrode. The small size of the reduction cathodic peak compared to the larger oxidation anodic peak is attributed to the initial low concentration of $\mathrm{PbSO}_{4}$ and the partial conversion of $\mathrm{Pb}$ to $\mathrm{PbSO}_{4}$. The reduction peak at $-559.1 \mathrm{mV}$ corresponds to the redox potential of the $\mathrm{Pb} / \mathrm{PbSO}_{4}$ redox couple when referenced to $\mathrm{Ag} / \mathrm{AgCl}_{2}$. The anodic peak positions of the other carbon loaded electrodes as shown in figure 4, are slightly shifted to higher potentials due to the presence of the carbons. The enhanced anodic discharge currents of the $2 \%$ and $4 \%$ carbon loaded electrodes as shown if figure 5 is clearly due to the added electroactive carbons of high nano-surface area. This confirms that the activated coconut shells carbons can be effectively utilized in the preparation of the lead carbon batteries. Notice however as seen in figure 6 that the reduction integral area (charge stored) of the $2 \%$ carbon loaded electrode is higher than that of the $4 \%$ carbon loaded unit. This occurrence is attributed to lead space restriction in the $4 \%$ carbon loaded unit. Conversely, figure 4 shows a much higher integral charge indicative of the electroactive carbon contribution to the capacitive effect. It is however noted that the electrodes did not present any double layer charge storage property. This we attribute to the direct mixing of the carbon to the $\mathrm{PbO}$ before processing into electrodes. Figure 5 shows the redox peaks decrease as the carbon loading increases beyond $4 \%$. This may be attributed to overloading of the electrode with the carbon beyond the electrolyte percolation level thereby restricting access to the lead surface. Since the mixed combination of $\mathrm{PbO}$ and carbon does not allow double layer behavior, the generated current drops as indicated. This result suggest that in the use of carbon in lead carbon plates, the $\mathrm{PbO}$ and Carbon should be applied as separate layers.

Electrochemical Impedance Spectroscopy: Electrolyte resistance recorded at near zero frequency spanned 0.18 $\Omega$ to $0.72 \Omega$. The variation was attributed to slight concentration changes in the electrolyte as the spectroscopy progressed The electrode with zero carbon exhibited the highest polarization impedance of $461.21 \Omega$. This was expected as the introduced carbons must have contributed to the ease of charge transfers for the active lead charges in the other electrodes. This phenomenon also peaked in the $4 \%$ carbon loaded electrode as demonstrated in the cyclic voltammetry result. This level of carbon loading seems to generate the most porous configuration leading to enhanced electrolyte penetration into the electrode structure. The highest impedance of $109.78 \Omega$ obtained for the $8 \%$ loaded unit was attributed to carbon blocking of electrolyte flow to the electroactive lead in the electrode interior.

\section{Conclusion}

Experimental grade negative lead carbon electrodes have been prepared and tested. They were produced with lead oxide obtained from hydrometallurgical recycled used lead acid battery materials and chemical activated coconut shells. Electrochemical test results indicated that about four percent conductive carbon mix with lead oxide is sufficient for the preparation of functional electrodes. High levels of electrode polarization impedances were however observed in the electrodes which were attributed to impurities and inadequate processing conditions.

\section{References.}

Calabeck M., Micka K., Krivak P., Baca P. (2006): Significance of carbon additive in negative lead - acid battery electrodes. Journal of power sources (158) 864-867.

Detchko Pavlov, Lead-Acid Batteries: Science and Technology. A Handbook of Lead-Acid Battery Technology and its Influence on the Product. $1^{\text {st }}$ ed., Elsevier Radarweg 29, 1000 AE Amsterdam, the Netherlands.2011.

D. Pavlov*, T. Rogachev, P. Nikolov, G. Petkova, (2008): Mechanism of action of electrochemically active carbons on the processes that take place at the negative plates of lead-acid batteries. Journal of Power Sources. (191) 58-75.

Enos D. (2012). Carbon Enhanced Lead Acid Batteries. Advanced Lead -Acid Consortium. http//www.alabc.org.about.

Farma R, M. Deraman, Awitrus E.T, I.A. Talib, R. Omar, J.G. Manjunatha, M.M. Ishak, N.H. Basri, B.N.M. Dolah. (2013). Physical and electrochemical properties of supercapacitor electrodes derived from carbon nanotube and biomass carbon. International Journal of Electrochemical science. 8(1):257-273

Fernadez M., Valenciano F., Trinidad F., Munoz N. (2011). The use of activated carbon and graphite for the development of lead-acid batteries for hybrid vehicle applications. Journal of power sources (195) $4458-$ 4469.

Grubs Tandy, 2009: Adsorption Isotherms, Methylene Blue on Activated Carbon Department of Chemistry, Unit 8271, Stetson University, Deland FL 32720.wgrubbs@stetson.edu .

Huanhuan Hao, Kailum Chen, Hao Liu, Hao Wang, Jingbing Liu, Kai Yang, Hui Yan. (2018): A Review of the Positive Electrode additives in lead-Acid Batteries. Int. J. Electrochem. Sci. (13) 2329 - 2340.

Imalerio, T.I., Amah, A.N., Onoja, D.A. Oberafo, A.A. (2014). Nano Pores Surface Area Evaluation in Palm kernel shells and Masonia wood derived Activated Carbons. Journal of Natural Sciences Research JNSR. 4 
(1): $95-100$.

Jaiswal A. Chalasani S.C. (2015): The role of carbon in the negative plate of lead-acid battery. Journal of energy storage (1) 15-21.

Junquing Pan, Xuan Zhang, Yanzhi Sun, Suang Song, Wei Li, Pingyu Wan. (2016) : Preparation of High Purity Lead Oxide from Spent Lead Acid Batteries via Desulfurization and Recrystallization in Sodium Hydroxide. Ind. Eng. Chem. Res. (55) $2059-2068$.

Micka K., Calabek M., Bacap., Krivak p., Labus R., BilkoR. (2009). Studies of doped negative valve-regulated lead-acid battery electrodes. Journal of power sources (191) 154-158.

Masaaki Shiomi, Takayuki Funato, Kenji Nakamura, Katsuhiro Takahashi, Masaharu Tsubota (1997): Effects of carbon in negative plates on cycle-life performance of valve-regulated lead/ acid batteries. Journal of Power Sources (64) 147-152.

P.T. Moseley, R.F. Nelson, A.F. Hollenkamp (2006): The role of carbon in valve-regulated lead-acid battery technology. Journal of power sources vol. (157) 3-10. 